\title{
Clinical ethics committees and the formulation of health care policy
}

Len Doyal St Bartholomew's and The Royal London School of Medicine and Dentistry, London

\begin{abstract}
For some time, clinical ethics committees (CECs) have been a prominent feature of hospitals in North America. Such committees are less common in the United Kingdom and Europe. Focusing on the UK, this paper evaluates why CECs have taken so long to evolve and assesses the roles that they should play in health care policy and clinical decision making. Substantive and procedural moral issues in medicine are differentiated, the former concerning ethicolegal principles and their paradigmatic application to clinical practice and the latter dealing with how such application should be negotiated in the face of disagreement and/or uncertainty. It will be argued that the role of CECs is both substantive and procedural. Provided that they do not overstep their appropriate moral and professional boundaries, CECs will be shown to have an important and positive function in improving hospital care within the UK and elsewhere.

(Fournal of Medical Ethics 2001;27 suppl I:i44-i49)
\end{abstract}

Keywords: Clinical ethics committees; policy; ethics decision making

\section{Introduction}

Over the past twenty-five years, a new player has emerged in North American health care. Clinical ethics committees (CECs) are now found in many hospitals and influence patterns of care. ${ }^{1}$ The functions of these committees include the formulation of hospital policy on ethicolegal matters, the provision of individual consultation about specific clinical cases and the organisation of education and training. ${ }^{2}$ Clinical ethics committees may also engage in the resolution of conflict between clinicians or patients, relatives and clinicians. ${ }^{3}$ More recently, some CECs have extended their policy brief to the review of institutional barriers to the conduct of good ethicolegal medicine within the hospitals they serve. ${ }^{4}$ Professional organisations and journals have been established to support those who work on CECs and to receive professional accreditation, hospitals must demonstrate their ability to deliver health care that reaches an acceptable ethicolegal standard. Many do so by reference to the work of their CECs. ${ }^{5}$ In North America, CECs have, therefore, become an integral part of the organisational infrastructure of hospitals.

Things could hardly be more different in hospitals within the United Kingdom. ${ }^{6}$ Here there are very few CECs. Even when such committees do exist, few problems may be referred to them and clinical staff may not even know of their existence. ${ }^{7}$ The reasons for this much slower development are complex but the following factors appear to have played a part. ${ }^{89}$ In North America there has been:

- a longer tradition of federal and state regulation of ethicolegal aspects of clinical activity (for example especially those concerning research);

- less tolerance of overt paternalism in medicine, along with a greater desire for transparency and accountability in decision making;

- a system of statute and common law which more actively supports patients' rights and a more accessible legal system;

- more willingness of patients and relatives to litigate or to make formal complaints over perceived breaches of professional duty;

- more authority vested in adults as legal proxies for treatment decisions concerning other adults, with resulting potential tensions with clinical staff, and

- more bioethics training programmes and thus more trained personnel to organise, advise and serve on CECs.

Factors such as these helped to convince many clinicians and clinical managers in North America that CECs can help to maximise the moral and legal standards of hospital care and may minimise the risks of litigation, complaint or running foul of state or federal authority. ${ }^{10}$ What lessons can we learn from the work of CECs in North America as they begin to expand in the UK?

This paper will explore the philosophical foundation of CECs, arguing that their presence is necessary for any coherent approach to the formulation and implementation of good ethicolegal policy in a modern hospital setting. A theoretical distinction will be developed between substantive and procedural ethics. It will be argued that the adequate resolution of difficult and complex "hard" ethicolegal cases in medicine requires collective discussion and debate similar to that already accepted as important in other aspects of clinical decision making (for example, case conferences). After outlining the types of work most important for properly structured and functioning CECs, the paper concludes by evaluating some of the constraints that may keep this work from being successfully implemented.

\section{Substantive ethics and CECs}

Despite the large numbers of CECs in North America, evidence suggests continued scepticism 
about them on the part of some clinicians. The fact that so few committees have been created in the UK indicates the existence of similar reservations. ${ }^{112}$ One often stated concern is that the collective character of CECs will contaminate the doctor-patient relationship because of its dependence on the trust patients place in their individual clinicians. ${ }^{13}$ Equally, there are fears that individual clinicians might abnegate personal responsibility for difficult ethicolegal decisions through becoming overly reliant on CECs. This blurring of clinical responsibility could also damage the clinical relationship. ${ }^{14}$ Some criticisms have also highlighted the potential ineffectiveness of "decision making by committee" and expressed frustration at arguments that trained senior clinicians might need ethicolegal support and advice from colleagues who are in different specialisations or have no medical training at all. ${ }^{15}$

On the face of it, such scepticism is understandable. Regulatory and professional bodies of all kinds within medicine are continuously disseminating information about the principles that should govern the conduct of good clinical practice. Undergraduate and postgraduate courses in ethics and law applied to medicine also play the same role. Thus if there is agreement within medicine about what should be done from an ethicolegal perspective then why shouldn't experienced clinicians be able to conduct their clinical life accordingly, without the help of a CEC?

In the UK, there certainly appears to be a professional consensus on such matters. Most published guidance about good ethicolegal practice in medicine embraces the same substantive moral principles and these are reflected in statute and case law. ${ }^{16-19}$ To an appropriate or reasonable standard, clinicians should: protect the life and health or their patients; respect their autonomy-their right to make competent and informed clinical choices on the basis of adequate information, and protect and respect patients justly and without prejudice.

The precise formulation of these principles is somewhat arbitrary. For example, Beauchamp and Childress famously characterise them as beneficence, non-maleficence, autonomy and justice. ${ }^{20}$ But however the details are spelled out in the many documents concerned, the substantive ethicolegal message is much the same. Similar agreement is to be found in various professional bodies in North America. ${ }^{2122}$ In both the UK and North America, a variety of legal judgments concerning the duties of care also reflect this common moral vision. ${ }^{23}$

A further reason for the commonality of such regulatory principles is their capacity to be derived from otherwise competing moral theories. For example, the duty to respect the autonomy of patients follows from arguments supporting the existence of the human right to bodily integrity, itself derivable from (among others) principles of rational self interest and human need. Yet the same duty also follows from utilitarian reasoning about the negative consequences for the doctor-patient relationship of not respecting autonomydisrespect leading to an increase in aggregate unhappiness. Finally, casuistic moral reasoning argues that the general consensus about the importance of respect for autonomy derives not from general philosophical arguments of whatever kind but from a host of individual cases to which diverse clinicians have the same moral reaction. Thus philosophers may and do disagree about the moral foundations of medicine but still agree about what constitutes good and bad clinical conduct. ${ }^{24}$ Therefore, it is hardly surprising that so much law in the UK, North America and elsewhere shares the same moral vision. It has evolved against the background of what is in effect a moral consensus.

Many clinicians question the need for CECs because they resent the suggestion that they are not perfectly capable of understanding their professional duties and conducting their practice in a way that is consistent with them. ${ }^{13}{ }^{15}$ While there may be an educational need for CECs to ensure that local clinical staff are up to date on the content and practical implications of national ethicolegal policies, any further intrusion into the conduct of clinical practice should be regarded as presumptuous, potentially harmful and unnecessary. To the degree that some clinicians do conduct themselves professionally and are blind to the moral and legal importance of certain basic standards of clinical performance, regulatory mechanisms already exist for their further education, discipline or possible exclusion from the medical profession. Education aside, therefore, CECs are argued to be both irrelevant and redundant.

\section{Procedural ethics and moral indeterminacy}

The fact that there is a general consensus about the moral and legal principles associated with the duties of care does not mean there is also agreement about how to interpret these principles in practice. The same point holds for agreement about the moral and legal status of particular examples of clinical conduct. Clinicians who concur about some examples may disagree about others - and they may do so citing the same moral or legal justification. ${ }^{24}$ This is the case for two reasons.

On the one hand, the formulation of each duty of care contains variables that are essentially open ended and subject to different interpretation. For example, what does it mean to protect life and health and respect autonomy to an "appropriate" or "professional standard" and do both "fairly"? While on one level of abstraction, there may be agreement about substantive principles, on a lower level this may be impossible because of other conflicting beliefs and values. Thus two clinicians may accept the duty to protect life and health but because of other disagreements about the moral status of the fetus or severely brain damaged patients may still disagree over issues pertaining to termination of pregnancy or the non-provision or withdrawal of life-sustaining treatment. Disagreements may occur for the same reason when trying 
to anticipate future legal judgments where common law is unclear.

On the other hand, substantive moral and legal principles may themselves conflict with each other and clinicians can disagree about how to resolve the conflict. For example, respect for confidentiality may be incompatible with the duty to protect the public. Similarly, when managing scarce resources, the duty to provide treatment to patients in need may conflict with the responsibility to do so justly. Justice may appear to dictate not treating some patients in order to protect the lives and health of others. There may be disagreement, however, about which patients fall into which categories.

When clinicians interpret the same duties of care in different ways or cannot agree about the resolution of conflict between such duties, they are thrown into a state of moral and legal indeterminacy. ${ }^{25}$ In such circumstances, there is no point in looking for help from the substantive moral or legal principles that are in question: for it is their susceptibility to conflicting interpretation that poses the problem. The moral indeterminacy may not be resolvable by the individuals who disagree. This may be because of poor communication between them or their unwillingness to depart from favoured interpretations of the substantive principles in dispute. For example, many moral arguments in medicine continue to question the boundaries of acceptable paternalism toward patients. The protagonists in this debate can be so entrenched that they often seem to be talking past each other, with little prospect of an agreed practical outcome. Yet the disputants may all still accept that clinicians should respect the autonomy of patients to an appropriate standard!

Unfortunately, appeals to "the law" can also be unhelpful in resolving such disagreements. ${ }^{26}{ }^{27}$ This is because there may also be dispute about what the law entails in clinical practice or because it is not regarded as a good guide to morally acceptable practice. As an example of the former, there has been much debate about the circumstances under which feeding and hydration can be withdrawn without the agreement of the court from patients who are severely brain damaged but not suffering from persistent vegetative state (PVS). Case law is not totally clear on the matter and published professional guidelines have had to proceed despite this. ${ }^{28}$ The degree to which the law may not be a guide to good practice is best illustrated by debates about informed consent. English law demands a low "professional" standard of disclosure of information about risks - still governed by the Bolam test-while the General Medical Council and the British Medical Association have now backed a higher standard. Thus clinicians can have a very good understanding of the law and still not be sure how to proceed in specific cases. They can also disagree about how to set professional standards higher than the current legal denominator. ${ }^{27}$

Yet clinical life must go on and moral and legal indeterminacy within medicine cries out for practical resolution. When negotiation about acceptable professional conduct breaks down between individuals, clinical policy should be formulated through a respected forum of wider debate, discussion and conflict resolution..$^{29}$ If a particular "hard case" poses dilemmas for clinicians and health care teams, good clinical practice requires a procedural means to generate the most rational course of action in the circumstances.

It has long been accepted that due process in law requires that contesting parties have an equal opportunity fairly to put their case before a judgment is given. The collective proceedings of court hearings are designed to achieve this goal. Similarly, at their best, research ethics committees try to ensure that their members represent the different types of expertise and experience required for optimally informed decision making-say, about the appraisal of risk-benefit ratio for a proposed clinical trial. They should also ensure that however much the views of members may differ, everyone has the same right to be heard and the vested interests of individuals are not allowed to determine conclusions. By this means final judgments can be made to embody the most rational compromise possible.

The practical resolution of moral and legal indeterminacy within clinical practice requires the same approach to optimising rational deliberation. ${ }^{30}$ At their best, CECs should take on this role through appropriate terms of reference, rules of debate and membership. Beginning with their terms of reference, these committees should serve two functions aside from education: pro-active policy formation and reactive consultation about particular ethicolegal dilemmas.

Clinical ethics committees should be pro-active in that they should formulate policies concerning good clinical care. These should create a feeling of institutional ownership of moral and legal principles that have been agreed nationally. This can be achieved through the translation of such principles into locally agreed language, along with paradigm examples of their appropriate application. Where there are disagreements about the implications of local policies for clinical practice, compromises must be reached which are deemed to be consistent with the law and other regulatory commitments (for example, GMC guidance). Second, CECs should also be reactive through providing a respected forum where clinicians can bring ethicolegal queries about particular cases, including disagreements about the duties of care between themselves, colleagues, patients or relatives. Here, the problem may just be educational - a clinician, for example, may be confused on a point of law or unaware of published and professionally agreed policies. However, the problem may also require some form of conflict resolution, as a result of helping those concerned to see the weaknesses or unforeseen and unacceptable consequences in their arguments, values and beliefs.

Pro-active decisions should always be taken by the CEC as a whole. Because these may affect all personnel in the hospital - the only health care 
environment that is the focus of this paper-a high level of accuracy about moral and legal matters will be of the utmost importance. The degree to which policies drafted by the committee are taken seriously will partly be a function of the respect which staff have for committee members and the past relevance and usefulness of their work. For this reason, it is essential that membership is seen to reflect a broad range of expertise-including that of informed lay members - and that attention is paid to the way in which new policies are presented and publicised. If they are not seen to be practically feasible, as well as academically informed, they will not be taken seriously, with potentially damaging consequences for both patients and their carers.

Because ethicolegal problems requiring a reactive and quick response are often brought by individual clinicians, they may require consultation with an individual member of the CEC who has relevant experience and training. ${ }^{31}$ Membership should include a professional bioethicist with a good understanding of medical law and a track record of engaging in such consultation. ${ }^{32}$ The commitment to confidentiality in the imparting of such individual advice will be of paramount importance. Any breakdown in trust between CEC representatives and clinical staff will be just as disastrous for successful ethicolegal consultation as it is for successful clinical consultation. Unless staff request otherwise, an outline of the details of consultations about individual cases should be brought back to the CEC to inform its future pro-active deliberations. There may be circumstances where reactive issues should be heard by either the whole CEC or a standing sub-committee that can meet in emergency session. Here, dilemmas will almost invariably be about the medical or surgical care of inpatients and may require conflict resolution. If the latter is the case, provision must be made for all contesting parties to have relevant access to the committee. $^{33}$

\section{Policy profiles: what should be done?}

The importance of procedures being in place for optimally rational decision making applies to the formulation of ethicolegal policy at all levels. Without appropriate expertise, discussion and debate, such policies are more likely to be ineffective and to reflect arbitrary rather than public interests. Therefore, it is hardly surprising that nationally agreed ethicolegal principles concerning the duties of clinical care have all been formulated by committees procedurally constituted in much the ways outlined. It should be equally unsurprising that a diverse range of such committees (for example in the UK, those of the GMC, the BMA or the royal colleges) have all reached much the same genera conclusions about these duties. The work of CECs, therefore, should be seen as carrying on these same traditions of collective deliberation, further articulating, applying and teaching the principles thus generated.

Because local CECs will always work against the background of more generally agreed policies, their own pro-active policies should take two forms. On the one hand, national guidance and legal judgments are often stated in long documents, the details of which busy clinicians cannot be expected to remember. It is therefore of particular importance that concise summaries be developed and disseminated in a manner believed by CEC members to be practically useful. On the other hand, it has already been noted that despite their detail, many national policies and guidelines can still be open-ended in their potential for different interpretation. Once CECs have reached agreement on a specific interpretation which is believed to be both consistent and practically feasible, this too must be communicated in a way which gives constructive and specific advice, with copies available to staff on all appropriate hospital wards. More detailed documentation about the reasons for the adoption of this interpretation should also be agreed, distributed to clinical managers and made available for inspection by all staff.

In illustration, two types of ethicolegal issues in medicine have traditionally dominated policy formation on CECs at both national and local levels. By far the most important has been, and will continue to be, problems concerning the non-provision or withdrawal of life-sustaining treatment. Within the UK and elsewhere, policy documents abound from respected organisations and their own clinical ethics committees. For example, the BMA has recently published a long and impressive policy statement about the circumstances in which clinical duty to protect life and health can be overridden. ${ }^{28}$ Yet the monograph is quite long and begs for a concise summary, including practical examples of how various open-ended waivers of this duty should be interpreted in clinical practice. It is one thing for the BMA to argue for the importance of a clinical consensus about decisions to withdraw life-sustaining treatment for children or adults. It is quite another for such a consensus to be regularly achieved. This will require policies designed and presented in ways that are calculated to facilitate team building and good communication.

The second most likely issue to demand pro-active CEC attention concerns the boundaries of obtaining informed consent to clinical treatment. Within the United Kingdom, the law offers scant guidance for good clinical practice in obtaining consent. It is still common for medical lawyers to state that there is no such thing in law as the doctrine of informed consent and that the standard of disclosure of information commanded by common law is very weak indeed. The Department of Health has hardly helped matters through failing to grasp the importance of raising professional standards in their own published guidance. ${ }^{34}$ As has been indicated, the BMA and GMC have taken a lead in their policy documents, advocating a higher standard of disclosure rather than the professional or "Bolam" standard incorporated in law. Yet these documents are written at such a general level that clinicians require more specific local policies that encourage them to improve their traditional 
patterns of obtaining consent and provide practical advice about how to do so. For example, CECs should review hospital consent forms, making it impossible to complete them without the inclusion of minimally acceptable information about diagnosis, treatment and risks. Concise advice should also be provided about how a higher standard of disclosure of information should be applied in practice.

Clinical ethics committees should also formulate local guidance about other areas of clinical life. These cover the spectrum of issues discussed in current texts on bioethics. Included should be local policies on (among others):

- confidentiality - improving the security of clinical records (especially in light of the 1998 Data Protection Act) and regulating the use of such records (for example for educational purposes) and their transmission between health care staff;

- relatives - clarifying the fact that in the UK, relatives cannot act as legal proxies for adult patients, along with the practical implications of this for good professional practice in consultations with carers;

- reproduction-advising on how best to implement professional and legal guidance on in vitro fertilisation (IVF) and other forms of assisted reproduction, on genetic screening and on good obstetric care (for example dealing with refusals of caesarean section);

- psychiatry - articulating the role of the duty psychiatrist throughout the hospital and the circumstances when incompetent patients or patients strongly thought to be incompetent, can be given emergency care without consent (for example in accident and emergency medicine), and

- resource allocation-formulating policies for the fair distribution of scarce resources for all clinical specialisations within the hospital, including the organisation of fair waiting lists, of transparent and effective triage and of the prioritisation of expensive drugs and equipment.

Clinical ethics committees should formulate such local policies and practical guidance for the hospital as a whole. Sometimes, however, the development of both will best occur in relation to the needs of particular clinical specialisations. ${ }^{35}$ When this is so, initial contact between the specialisation and the CEC should occur through the most appropriate committee member and, again with appropriate consent, details of the consultation should be reported back to the committee.

Constraints on the success of CEC policies

There are three key constraints on the potential success of CECs in formulating local policy and providing a reserve of individual consultants who can work with colleagues to put it into practice.

First, it is essential that CECs do not exceed their terms of reference as bodies that advise on, but do not formulate, clinical policy about specific patients. ${ }^{13}$ This should remain the responsibility of their clinicians. Those who have been hostile to the creation and operation of CECs have been most concerned about their potential for clinical interference and for good reason. Clinical relationships with patients are highly individual in character and depend for their success on a strong bond of trust. If patients come to believe that "strangers at the bedside" are making key decisions then this bond may be undermined. ${ }^{8}$ If patients or relatives believe that a committee rather than their doctor is making important decisions about their specific care then accountability will become blurred, with potentially disastrous consequences for effective counselling and communication. If CECs overreach their advisory role, clinicians may react by not taking seriously policies which have been properly formulated and will improve patient care. ${ }^{36}$ Therefore, the terms of reference of CECs should be publicised, making clear their advisory status as regards individual or collective consultation.

Second, the long term success of CECs depends on much more than the theoretical coherence and practical feasibility of the policies they create. The real test of success will be the extent to which clinical staff actually implement these policies. Without appropriate training, however, implementation will at best be patchy. For example, it is now BMA and United Kingdom Central Committee for Nursing and Health Visiting (UKCC) policy that most competent adults should consent to a do not resuscitate (DNR) code in their notes. Many hospitals have also formulated policies that say the same. Yet clinicians sometimes ignore this advice and still administer DNR codes without consent. They may do so because they are uncomfortable with discussing the non-provision of resuscitation with very sick patients and they have not received any training or practical advice about how to have such a discussion. ${ }^{37}$ Similarly, there is extensive evidence that clinicians can be poor communicators. Even if they accept the local policies about the moral and legal importance of informed consent, they may hardly be in a position to act accordingly. ${ }^{38}$ Therefore, CECs should never rest content with the role of policy formation. They should press hospital administrations to resource appropriate training programmes.

Finally, CECs must address the fact that the effective implementation of ethicolegal policy requires supportive institutional structures. ${ }^{4}$ For example, if no mechanisms exist for monitoring the degree to which staff conform to the committee's published policies, the success of its work will be impossible to judge. Similarly, the CEC may formulate local ethicolegal policies but it will not have the capacity or authority to disseminate them. The extent to which the institution does so will signal to staff its commitment to the work of the committee. Furthermore, unless institutional structures are in place to ensure that recommendations of CECs can be practically implemented, they will remain little more than devalued or ignored moral abstractions. For example, it is one thing for local policies to stress the professional importance of the confidentiality of clinical records. It is quite another 
for the actual management of these records and the maintenance of their security to be done in ways that make the strict preservation of privacy a practical proposition. CECs should keep such institutional issues under review and, when appropriate, press them home to hospital management.

\section{Conclusion}

This paper has explored the background to and need for CECs in hospital medicine. To be optimally rational, the creation and effective use of substantive moral and legal principles must be grounded in collective discussion. In the face of moral and legal indeterminacy, such discussion should conform to procedural principles that ensure the participation of those with relevant expertise and effective, fair debate between them. Provided that CECs work to such principles and their members are trained to do so then there is every reason to believe they can make an extremely positive contribution to improving clinical practice and the general quality of health care. ${ }^{39}$ At their best, research ethics committees have made just such a contribution to good research practice in clinical medicine. Resistance to the creation of CECs risks, therefore, the appearance of self serving. Such resistance is particularly ironic in a country where the professional reputation of doctors has recently come under attack for poor ethicolegal practice. There is no reason any longer to tolerate a double standard where rigorous regulation of clinical activity is confined only to research..$^{40} \mathrm{~A}$ high standard of clinical care is essential, whatever the context of its delivery. Properly organised and functioning CECs can help to ensure such a standard through the active involvement of clinicians themselves. ${ }^{41}{ }^{42}$

\section{Acknowledgement}

I wish to express my thanks to Professor Lesley Doyal, Dr Alastair McDonald and Dr Brian Colvin.

Len Doyal, BA, MSc, is Professor of Medical Ethics at St Bartholomew's and The Royal London School of Medicine and Dentistry, Queen Mary and Westfield College, University of London and Honorary Consultant at Barts and the Royal London NHS Trust.

\section{References}

1 Csikai EL. The status of hospital ethics committees in Pennsylvania. Cambridge Quarterly of Healthcare Ethics 1998;7:104-7.

2 Blake DC. The hospital ethics committee. Healthcare's mora conscience or white elephant? Hastings Center Report 1992; 2:6 11 .

3 Nelson RM, Shapiro RS. The role of an ethics committee in resolving conflict in the neonatal intensive care unit. Fournal of Law, Medicine E Ethics 1995;23:27-32.

4 Potter RL. On our way to integrated bioethics: clinical organisational/communal. Fournal of Clinical Ethics 1999;10: 171-77.

5 Joint Commission for Accreditation of Healthcare Organisations. 1996 Comprehensive manual for hospitals. Chicago: JCAHO, 1996: 95-7.

6 Slowther A, Hope T, Bunch C. Clinical ethics committees in the UK. Fournal of the Royal College of Physicians of London 1999;33:202-3.
7 Wood KA, Ellis S. A clinical ethics committee in a small health service trust [letter]. Fournal of Medical Ethics 1999;25:420 8 Rothman D. Strangers at the bedside. New York: Basic Books, 1991.

9 Thornton JG, Lilford RJ. Clinical ethics committees. British Medical fournal 1995;311:667-9.

10 Heilicser B, Meltzer D, Siegler M. The effect of clinical medical ethics consultation on healthcare costs. Fournal of Clinical Ethics 2000;11:31-8.

11 Gillon R. Clinical ethics committees-pros and cons. Fournal of Medical Ethics 1997;23:203-4.

12 Slowther A, Bunch C, Woolnough B, Hope T. Clinical ethics support services in the UK: an investigation of the current prosupport services in the UK: an investigation of the current pro-
vision of ethics support to health professionals in the UK. Fourvision of ethics support to health professio
nal of Medical Ethics 2000;27(supp):i3-i9.

13 Siegler M. Ethics committees: decisions by bureaucracy. Hastings Center Report 1986;16:22-4.

14 Davies L, Hudson LD. Why don't physicians use ethics consultation? fournal of Clinical Ethics 1999;10:125.

15 Scofield GR. Ethics consultation: the least dangerous profession? Cambridge Quarterly of Healthcare Ethics 1993;2:417-25.

16 General Medical Council. Good medical practice. London: GMC, 1995.

17 General Medical Council. Seeking patients' consent: the ethical considerations. London: GMC, 1998: 2-9.

18 British Medical Association. Medical ethics today. London: BMA, 1993: 7-11.

19 The Senate of Surgery of Great Britain and Ireland. The surgeon's duty of care. London: Royal College of Surgeons, 1997.

20 Beauchamp T, Childress JF. Principles of biomedical ethics. New York: Oxford University Press, 1994

21 American Medical Association. Code of medical ethics. Chicago: AMA, 1997.

22 Canadian Medical Association. Code of ethics. Ottawa: CMA,

23 Kennedy I, Grubb A. Medical law-text and materials. London: Butterworths, 1994

24 Jonsen AR, Toulmin S. The abuse of casuistry: a history of moral reasoning. Berkeley: University of California Press, 1988

25 Doyal L. Medical ethics and moral indeterminacy. Fournal of Law and Society 1990;17:1-17.

26 Spielman B. Invoking the law in ethics consultation. Cambridge Quarterly of Healthcare Ethics 1993;2:457-67.

27 Spielman B. Organisational ethics programs and the law. Cambridge Quarterly of Healthcare Ethics 2000; 9:218-29.

28 British Medical Association. Withholding and withdrawing life-prolonging medical treatment. London: BMA, 1999.

29 Ross JW. Case consultation: the committee or the clinical conRoss JW. Case consultation: the com
sultant. HEC Forum 1990;2:89-98.

30 Doyal L, Gough I. A theory of human need. London: Macmillan, 1991: 116-41.

31 Cohen CB. Avoiding "cloudcuckooland" in ethics committee case review: matching models to issues and concerns. Law, Medicine E Healthcare Ethics 1992;20:294-9.

32 Fox MD, Caplan A. Paradigms for clinical ethics consultation practice. Cambridge Quarterly of Healthcare Ethics 1998;7:30814.

33 Agich GJ, Younger SJ. For experts only? Access to hospital ethics committees. Hasting Center Report 1991;Sept-Oct:17-25.

34 Department of Health. A guide to consent for examination to treatment. London: $\mathrm{DoH}, 1992$.

35 Schwartz RL, Kushner T. The role of institutional and community based ethics committees in the debate on euthanasia and physician-assisted suicide. Cambridge Quarterly of Healthcare Ethics 1996;5:121-30.

36 Tulsky JA, Fox E. Evaluating ethics consultation: framing the Tulsky JA, Fox E. Evaluating ethics consultation:
questions. Fournal of Clinical Ethics 1996;7:109-15.

37 Mello M, Jenkinson C. Comparison of medical and nursing attitudes to resuscitation and patient autonomy between a British and an American teaching hospital. Social Science and Medicine 1998;46:415-24.

38 Hall A. The role of effective communication in obtaining informed consent. In: Doyal L, Tobias J, eds. Informed consent in medical research. London: BMJ Books, 2000:291-8.

39 Leeman CP, Fletcher JC, Spencer EM, Fry-Revere S. Quality control for hospitals' clinical ethics services: proposed standards. Cambridge Quarterly of Healthcare Ethics 1997;6:257-68.

40 Chalmers I, Lindley R. Double standards in informed consent. See reference 38:266-75.

41 Larcher VF, Lask B, McCarthy JM. Paediatrics at the cutting edge: do we need clinical ethics committees? Fournal of Medical Ethics 1997;23:245-9.

42 Slowther A, Underwood $M$. Is there a demand for a clinical advisory service in the UK? Fournal of Medical Ethics 1998;24: 207. 